Journal of Clinical Investigation

Vol. 41, No. 2, 1962

\title{
STUDIES ON NORMAL AND LEUKEMIC LEUKOCYTES. III. PYRIDINE NUCLEOTIDES *
}

\author{
By ROBERT SILBER, $†$ BEVERLY W. GABRIO ANd F. M. HUENNEKENS with the \\ TECHNICAL ASSISTANCE OF MARGARET ALBRECHT
}

(From the Department of Biochemistry, University of Washington and King County Blood Bank, Seattle, Wash.)

(Submitted for publication August 14, 1961 ; accepted September 18, 1961)

The levels of the four pyridine nucleotide coenzymes, DPN, ${ }^{1}$ DPNH, TPN, and TPNH, have been determined in a variety of normal and neoplastic tissues (1). Similar comprehensive data for human leukocytes have not been available previously, although Beck (2) has reported values for total pyridine nucleotides in normal subjects and patients with chronic leukemia. In addition, some corollary information is available from the work of Ondarza (3) who measured DPN levels in whole blood samples.

In the present communication the levels of DPN, DPNH, TPN, and TPNH have been determined in normal human leukocytes (14 subjects) and in cells of 31 patients with chronic lymphatic, chronic myelocytic, and acute leukemia.

\section{EXPERIMENTAL}

Materials and methods. Glucose-6-phosphate dehydrogenase, glucose-6-phosphate, DPN, DPNH, TPN, TPNH, and Tris were obtained from the Sigma Chemical Co., crystalline yeast alcohol dehydrogenase from C. F. Boehringer and Sons, EDTA from the J. T. Baker Chemical Co., acetaldehyde from Eastman Organic Chemicals, nicotinamide from the Nutritional Biochemicals Corp., and sodium heparin (10 $\mathrm{mg}$ per $\mathrm{ml}$ ) from Invenex Co., San Francisco, Calif. DPNase was prepared from beef spleen by the method of Zatman, Kaplan and Colowick (4).

Leukocytes were isolated by the following technique which will be described in detail elsewhere (5). Blood samples were collected in heparin $(2 \mathrm{mg}$ per $100 \mathrm{ml}$ of blood) or in acid citrate dextrose (National Institutes

* This work was supported by Grant P-203 from the American Cancer Society.

$\dagger$ Special Fellow of the National Cancer Institute, United States Public Health Service.

1 The following abbreviations are used: DPN and TPN, di- and triphosphopyridine nucleotide; $\mathrm{DPNH}$ and TPNH, reduced DPN and TPN; EDTA, disodium ethylenediamine tetraacetate (dihydrate); Tris, Tris(hydroxymethyl) aminomethane; and DPNase, diphosphopyridine nucleotidase. of Health, Formula A). All subsequent operations were carried out at $4^{\circ} \mathrm{C}$. Two vol of 3 per cent dextran in 0.9 per cent $\mathrm{NaCl}$ was added to 1 vol of blood in a glass-stoppered cylinder. The mixture was inverted carefully several times and allowed to sediment under gravity until a clear separation of the red cell layer was apparent. The supernatant fluid, containing the leukocytes, was removed and centrifuged for 4 minutes at $180 \mathrm{G}$. The supernatant fraction, containing platelets, was discarded and the collected cells were washed in 5 vol of 0.9 per cent $\mathrm{NaCl}$ and centrifuged for 4 minutes at $500 \mathrm{G}$. After removal of the supernatant fluid, selective lysis of remaining erythrocytes was accomplished by vigorous mixing of the leukocyte-rich layer with 3 vol of distilled water for 30 seconds, followed by the addition of 1 vol of $0.6 \mathrm{M} \mathrm{KCl}$ to restore tonicity. Two subsequent washes with 10 vol of 0.9 per cent $\mathrm{NaCl}$ were necessary to free the leukocyte fraction of contaminating hemoglobin. Finally, the leukocytes were suspended in 0.9 per cent $\mathrm{NaCl}$.

Extraction of pyridine nucleotides from leukocytes. The technique of Bassham, Bert, Hems and Loening (6) was used for the extraction and measurement of pyridine nucleotides, although several modifications were necessary in order to adapt the method to leukocytes. A convenient working sample consists of a suspension of $10^{\circ}$ leukocytes in $2 \mathrm{ml}$ of 0.9 per cent $\mathrm{NaCl}$. One $\mathrm{ml}$ of this suspension was pipetted directly into each of two homogenizing vessels of 5 to $30 \mathrm{ml}$ capacity (Virtis Co.) immersed in a boiling water bath. One vessel (A) contained $2.5 \mathrm{ml}$ of $0.1 \mathrm{M}$ Tris- $\mathrm{HCl}$ buffer $(\mathrm{pH} 8.2), 0.5$ $\mathrm{ml}$ of $1 \mathrm{~N} \mathrm{HCl}$, and $0.5 \mathrm{ml}$ of $0.5 \mathrm{M}$ nicotinamide. The other vessel $\left(\mathrm{A}^{\prime}\right)$ contained $2.5 \mathrm{ml}$ of $0.1 \mathrm{M}$ Tris- $\mathrm{HCl}$ buffer ( $\mathrm{pH} 8.2$ ), $0.7 \mathrm{ml}$ of $1 \mathrm{~N} \mathrm{NaOH}$, and $0.5 \mathrm{ml}$ of $0.5 \mathrm{M}$ nicotinamide. After addition of the leukocyte suspension, the vessels were kept in the boiling water bath for 30 seconds. The vessels were removed from the bath and two drops of 2-octanol were added to each in order to prevent foaming. The mixtures were ho'mogenized for 2 minutes at 45,000 rpm in the Virtis-45 homogenizer and returned to the boiling water bath for an additional 2 minutes. The samples ( $A$ and $A^{\prime}$ ) were quickly frozen in a dry ice-methoxyethanol bath, thawed, restored to $\mathrm{pH} 8.2$ with $1 \mathrm{~N} \mathrm{NaOH}$ or $1 \mathrm{~N} \mathrm{HCl}$, and centrifuged at $10,900 \mathrm{G}$ for 15 minutes in the International refrigerated centrifuge, model PR-2; the soluble fractions were retained for the measurement of coenzyme levels. 
Quantitative measurement of pyridine mucleotides. Sample A contains DPN and TPN; sample $A^{\prime}$ contains DPNH and TPNH, as well as any DPN and TPN resulting from oxidation of the reduced forms at the elevated temperatures used during the extraction procedure. Sample A was processed as follows: $0.1 \mathrm{ml}$ of $0.1 \mathrm{M}$ glucose-6-phosphate and $0.1 \mathrm{ml}$ of glucose-6-phosphate dehydrogenase ( 0.05 Kornberg units) were added to $1 \mathrm{ml}$ of solution $\mathrm{A}$ and the mixture was allowed to stand at room temperature (about $25^{\circ} \mathrm{C}$ ) for 20 minutes. Sample $A^{\prime}$ was divided into 2 fractions ( $B$ and $C$ ) and treated as follows: $1 \mathrm{ml}$ of $\mathrm{B}$ was treated with $0.06 \mathrm{ml}$ of $1 \mathrm{~N} \mathrm{HCl}$ and the sample was allowed to stand at room temperature for 5 minutes; $1 \mathrm{ml}$ of $\mathrm{C}$ was treated with $0.06 \mathrm{ml}$ of $1 \mathrm{~N} \mathrm{NaOH}$ and the mixture was incubated for 15 minutes at $60^{\circ} \mathrm{C}$. Samples $\mathrm{B}$ and $\mathrm{C}$ were readjusted to $\mathrm{pH} 8.2$ with $1 \mathrm{~N} \mathrm{NaOH}$ and $1 \mathrm{~N} \mathrm{HCl}$, respectively. Sample B was then treated with glucose-6phosphate and glucose-6-phosphate dehydrogenase as described above. Sample C was incubated for 20 minutes at room temperature with $0.1 \mathrm{ml}$ of $0.01 \mathrm{M}$ acetaldehyde, $0.1 \mathrm{ml}$ of alcohol dehydrogenase $(30 \mathrm{U})$, and $0.1 \mathrm{ml}$ of $0.035 \mathrm{M}$ EDTA. The amounts of glucose-6-phosphate dehydrogenase and alcohol dehydrogenase were present in at least a tenfold excess over that required for TPN reduction and $\mathrm{DPNH}$ oxidation during the indicated time period.

Analyses of samples $\mathrm{A}, \mathrm{B}$, and $\mathrm{C}$ for pyridine nucleotide content followed the fluorometric procedure of Bassham and co-workers (6), except that aliquots taken for analyses were increased to $0.2 \mathrm{ml}$ and the other reagents were increased proportionally. Fluorometric measurements were made with the G. K. Turner fluorometer using the following filters: primary Turner 7-60, secondary Turner 75, 2A, and Corning 4308.

\section{RESULTS AND DISCUSSION}

The technique of Bassham and associates (6) for the measurement of the four pyridine nucleotides (DPN, DPNH, TPN, and TPNH) is based on the fact that the oxidized pyridine nucleotides may be extracted by an acidic medium without destruction, while the reduced forms can be extracted by a basic medium. Quantitation of the extracted pyridine nucleotides is accomplished by conversion of the oxidized forms to a fluorescent derivative by treatment with a strong base. $\mathrm{DPNH}$ is converted to DPN with acetaldehyde and alcohol dehydrogenase, while TPNH is treated simultaneously with the oxidizing agent, $\mathrm{H}_{2} \mathrm{O}_{2}$, and base.

Prior to the application of this method to leukocytes, the pyridine nucleotide levels in the livers of 5 Sprague-Dawley rats were measured and the following values were obtained (expressed as

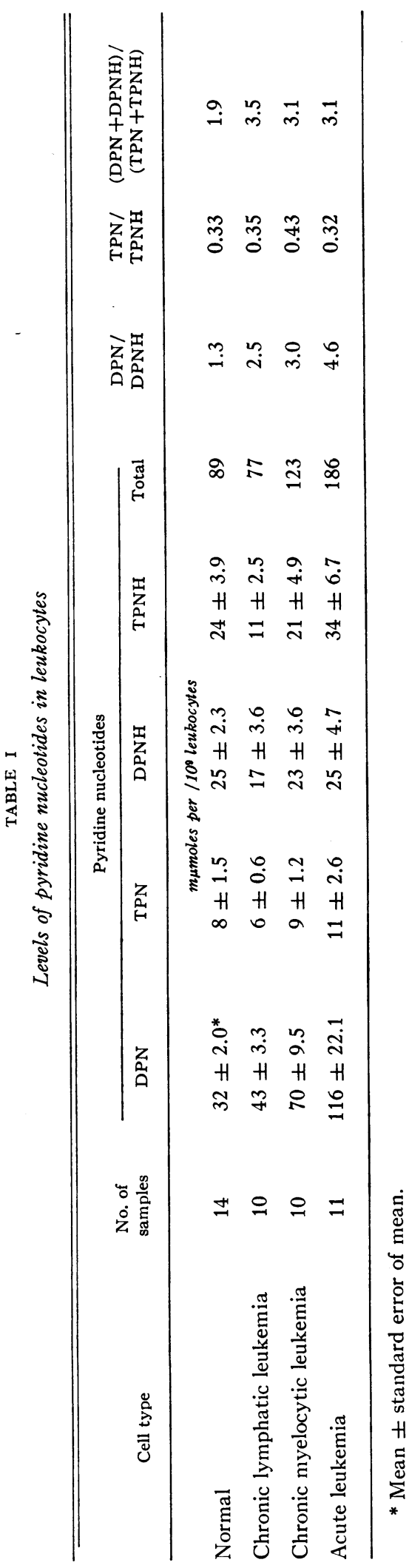


millimicromoles per gram wet weight): DPN, $505 \pm 41 ; \mathrm{DPNH}, 165 \pm 19 ; \mathrm{TPN}, 81 \pm 27$; and $\mathrm{TPNH}, 375 \pm 55$. These results are in good agreement with data from other investigations $(1,6)$.

There are several potential sources of error which must be considered in any method for the measurement of pyridine nucleotide levels in leukocytes. For example, the elapsed time is about 90 minutes between the collection of blood and the isolation of leukocytes by the procedure described in the Experimental section. This delay is greater than the time required for the processing of most other animal tissues. Some indication of the magnitude of this effect is shown by the fact that a 20 per cent decrease in the levels of oxidized coenzymes is noted if the leukocytes, after isolation, are allowed to stand for 1 hour at $4^{\circ} \mathrm{C}$. The decrease in pyridine nucleotides was even more rapid in leukocyte lysates; a similar effect has been noted previously in other tissues (7). In view of the potential lability of cellular pyridine nucleotides, care was taken to process and analyze the normal and leukemic blood samples under identical conditions.

Duplicate determinations of DPN on a particular leukocyte sample agreed to within 15 per cent, whereas duplicate assays of DPNH or TPNH were within 20 per cent agreement. The low level of TPN in the leukocyte makes it difficult to obtain close agreement between duplicate determinations. The recovery of DPN, admixed with the cells prior to homogenization, was about 85 per cent and that of TPNH about 80 per cent.

Table I contains a summary of the pyridine nucleotide levels in the leukocytes of 14 normal subjects and 31 patients with leukemia. The most striking fact which emerges from these data is that the DPN level is greatly elevated in acute leukemic cells in comparison with normal cells. The average level of DPN in acute leukemia is $116 \mathrm{~m} \mu$ moles (range, 37 to 233 ) per $10^{9}$ leukocytes, which is significantly increased $[\mathrm{p}<0.01$ (8)] above the mean level, $32 \mathrm{~m} \mu$ moles (range, 19 to 43 ) per $10^{9}$ cells, in normal subjects. It should be noted that in only 2 of the 11 patients with acute leukemia (namely, a 4 week old mongoloid baby with acute lymphatic leukemia and a 42 year old woman with acute myeloblastic leukemia) were the values low enough to overlap with the upper limit of the normal range. The amount of DPN found in leukocytes of chronic myelocytic leukemia [ $70 \mathrm{~m} \mu$ moles (range, 35 to 98 ) per $10^{9}$ cells] is also significantly greater $(p<0.01)$ than normal, while the level in chronic lymphatic leukemia [43 m $\mu$ moles (range, 26 to 60 ) per $10^{9}$ cells] is not appreciably greater than normal.

Additional experiments were performed in order to establish further the validity of the elevated DPN level in cells of acute and chronic myelocytic leukemia. The acid extract (sample A) of cells from a patient with chronic myelocytic leukemia was treated for 15 minutes with beef spleen DPNase (4) prior to the assay for DPN. Under these conditions no DPN was detected, in contrast to the control experiment, omitting the DPNase step, in which $14 \mathrm{~m} \mu$ moles of DPN per $\mathrm{ml}$ was found. In two acute leukemic samples, the elevated DPN level permitted this nucleotide to be measured directly with alcohol dehydrogenase (9); the values were in close agreement with those obtained by the fluorometric method. In view of the low concentration of the other pyridine nucleotides and the small quantity of leukocytes generally available, it was not feasible to use enzymatic assays for the routine determination of these nucleotides.

In contrast to the DPN data, the levels of TPN, TPNH, and DPNH in leukemic leukocytes were comparable to those of normal cells, except that the levels of DPNH and TPNH in chronic lymphatic leukemic cells are slightly lower than the corresponding normal values. Conversely, the elevated DPN level in the latter cells is interesting, since the small size of lymphocytes might be expected to result in a uniformly lower level of all the nucleotides when expressed per $10^{9}$ cells.

The data in Table I may be compared with the results of Beck (2) who used the fluorometric method of Levitas and associates (10) for the estimation of pyridine nucleotides in acid extracts of leukocytes. Since acid extraction largely destroys the reduced forms of the pyridine nucleotides, Beck's values, therefore, represent the sum of DPN and TPN ; these compounds are indistinguishable by the fluorometric method employed. With the use of this procedure, Beck reported essentially no difference in the values for the total pyridine nucleotides (DPN and TPN) in normal cells and cells of chronic lymphatic and chronic 
myelocytic leukemia. No data were available for acute leukemic cells. However, in the present investigation, the combined levels of DPN and TPN (cf Table I) in both chronic myelocytic and acute leukemia are elevated in comparison with the levels in normal and chronic lymphatic leukemia cells.

In addition to the absolute values for the pyridine nucleotides, further information is obtained by calculation of certain ratios ; i.e., DPN/DPNH, $\mathrm{TPN} / \mathrm{TPNH}$, and $(\mathrm{DPN}+\mathrm{DPNH}) /(\mathrm{TPN}+$ $\mathrm{TPNH})$. It is apparent from these ratios in Table I that in normal leukocytes, as in most other tissues, the total diphosphopyridine nucleotide $(\mathrm{DPN}+\mathrm{DPNH})$ is about twofold higher than the total triphosphopyridine nucleotide (TPN + TPNH). Furthermore, the diphosphopyridine nucleotide is distributed about equally between the oxidized and reduced forms (DPN/DPNH $=$ 1.3), while the triphosphopyridine nucleotide exists to a greater extent in the reduced form (TPN/ $\mathrm{TPNH}=0.33$ ). On the other hand, with the various types of leukemic cells, the elevated DPN results in increased ratios of $\mathrm{DPN} / \mathrm{DPNH}$ and $(\mathrm{DPN}+\mathrm{DPNH}) /(\mathrm{TPN}+\mathrm{TPNH})$; the TPN $/$ TPNH ratio is not changed appreciably.

The question may be raised whether the elevated level of DPN in acute and chronic myelocytic leukemia is caused by an increased rate of DPN synthesis or by a decrease in DPN destruction. The former possibility seems more likely in the metabolically active, immature leukemic leukocyte. In this respect, it may be recalled that Ciotti and colleagues (11) have reported that two DPN antagonists-2-amino-1,3,4-thiadiazole and 2 -ethylamino-1,3,4-thiadiazole-are effective in the treatment of L-1210 mouse leukemia, and these authors have suggested that the efficacy of these compounds as antitumor agents may be related to their demonstrable incorporation into DPN via the enzyme, DPNase.

Eight of the patients with acute leukemia were untreated at the time of the initial measurements, and there was no relationship between the initial leukocyte count and level of DPN. In two cases, a decrease of about 40 per cent in the elevated DPN level, associated with a decrease in the leukocyte count and immature cells, was observed during the course of 6-mercaptopurine therapy. The level of DPN in three untreated patients re- mained constant in several determinations made over a period of 2 weeks.

Finally, the present data reveal several differences in the level of pyridine nucleotide coenzymes in the human leukemic leukocyte as compared with other neoplasms. Although the present investigation has demonstrated an elevated DPN level in acute and chronic myelocytic leukemic cells, the DPN level of tumors, in general, is $d e$ creased in comparison with normal tissues (12). Furthermore, Glock and McLean (13) have reported that TPN and TPNH are virtually absent in many neoplastic tissues, but this is at variance with the present results with leukemic leukocytes.

\section{SUMMARY}

The levels of oxidized and reduced pyridine nucleotides (DPN, DPNH, TPN, and TPNH) in normal and leukemic leukocytes have been determined fluorometrically by a modification of the method of Bassham, Birt, Hems and Loening (6). In general, the levels are comparable in normal and leukemic cells, with the exception that the DPN content in cells from acute leukemia patients was considerably greater than normal. The DPN level in cells from chronic myelocytic leukemia patients was intermediate between the normal and acute leukemia values.

The relative amounts of the individual pyridine nucleotides in normal human leukocytes resembles the pattern found in rat liver. The relative amounts of DPN and TPNH in human leukemic cells are higher than those reported for various solid tumors.

\section{ACKNOWLEDGMENTS}

The authors are indebted to Drs. J. R. Czajkowski, D. H. Coleman, Q. B. De Marsh, and D. M. Donohue for providing us with blood specimens.

\section{REFERENCES}

1. Kaplan, N. O. The pyridine coenzymes in The Enzymes, 2nd ed, P. D. Boyer, H. Lardy and $\mathrm{K}$. Myrbäck, Eds. New York, Academic Press, 1960, vol. 3, Part B, p. 105.

2. Beck, W. S. A kinetic analysis of the glycolytic rate and certain glycolytic enzymes in normal and leucemic leucocytes. J. biol. Chem. 1955, 216, 333.

3. Ondarza, R. N. Free nucleotides in normal and leukemic blood cells. Acta Physiol. lat.-amer. 1960, $10,129$. 
4. Zatman, L. J., Kaplan, N. O., and Colowick, S. P. Inhibition of spleen diphosphopyridine nucleotidase by nicotinamide: An exchange reaction. J. biol. Chem. 1953, 200, 197.

5. Bertino, J. R., Alenty, A., Silber, R., Gabrio, B. W., and Huennekens, F. M., Studies on normal and leukemic leukocytes. IV. Levels of tetrahydrofolate-dependent enzyme systems. In preparation.

6. Bassham, J. A., Birt, L. M., Hems, R., and Loening, U. E. Determination of the reduced and oxidized pyridine nucleotides in animal tissues. Biochem. J. 1959, 73, 491.

7. Handler, P., and Klein, J. R. The inactivation of pyridine nucleotides by animal tissues in vitro. J. biol. Chem. 1942, 143, 49.

8. Edwards, A. L. Statistical Analysis for Students in Psychology and Education. New York, Rinehart, 1946 , p. 330 .
9. Racker, E. Crystalline alcohol dehydrogenase from baker's yeast. J. biol. Chem. 1950, 184, 313 .

10. Levitas, N., Robinson, J., Rosen, F., Huff, J. W., and Perlzweig, W. A. The fluorescent condensation product of $\mathrm{N}^{\prime}$-methylnicotinamide and acetone. III. A rapid fluorometric method for the determination of the total pyridine nucleotides in the red blood cells. J. biol. Chem. 1947, 167, 169.

11. Ciotti, M. M., Humphreys, S. R., Venditti, J. M., Kaplan, N. O., and Goldin, A. The antileukemic action of two thiadiazole derivatives. Cancer Res. 1960, 20, 1195.

12. Jedeikin, L. A., and Weinhouse, S. Metabolism of neoplastic tissue. VI. Assay of oxidized and reduced diphosphopyridine nucleotide in normal and neoplastic tissues. J. biol. Chem. 1955, 213, 271.

13. Glock, G. E., and McLean, P. Levels of oxidized and reduced diphosphopyridine nucleotide and triphosphopyridine nucleotide in tumours. Biochem. J. 1957, 65, 413. 